\title{
Fracture initiation and crack propagation of acrylonitrile-butadiene-styrene (ABS) in organic solvents
}

\author{
Y. W. MAI* \\ Department of Mechanical Engineering, Rheology and Fracture Group, University of \\ Michigan, Ann Arbor, Michigan, USA
}

The effects of organic liquid environments on the fracture behaviour of acrylonitrilebutadiene-styrene (ABS) have been investigated. Fracture initiation experiments showed that $K_{\mathrm{i}}^{2},\left(K_{\mathrm{i}}\right.$ being the stress intensity factor at crack/craze initiation), could be meaningfully correlated with the solvent solubility parameter $\left(\delta_{s}\right)$ of the different liquid environments and had a minimum value at $\delta_{\mathrm{s}}=\delta_{\mathrm{p}}$, where $\delta_{\mathrm{p}}$ was the solubility parameter of ABS. For the range of organic liquids used, hydrogen bonding did not have any significant effects on the correlations. It was demonstrated that the $K_{i}^{2}-\delta_{s}$ correlations could also be usefully extended to other materials such as plain and glass-filled polystyrenes. At a common crack speed $(\dot{a})$, the fracture toughness $(R)$ values in "crazing" liquids (i.e. alcohols) were greater than those in "cracking" solvents (i.e. acetone, benzene, toluene, etc.) which usually caused a "dissolution" effect on the plastic. From crack propagation experiments, and using fracture mechanics analyses, definite $R(\dot{a})$ and $K_{\mathrm{c}}(\dot{a})$ relationships for ABS immersed in toluene, carbon tetrachloride and methanol were determined. These experimental results showed that crack propagation was relaxation controlled and agreed well with a recent theoretical analysis due to Williams and Marshall for environmental crack and craze growth in polymers. Finally, SEM pictures were presented to show the remarkable differences in the fracture morphologies of ABS in both "crazing" and "cracking" liquid environments.

\section{Introduction}

Many polymeric materials when exposed to unfavourable liquid environments, may undergo pre-mature failure by crazing or cracking. Some common examples are: polyethylene in methanol [1], polymethylmethacrylate in organic solvents $[2-9]$, polycarbonate and polystyrene $[10,11]$ in a series of alcohols.

Fracture mechanics have been used successfully to describe the mechanics and kinetics of craze or crack initiation and propagation in many polymeric materials immersed in organic solvents. For

example, it has been found that craze or crack initiation in PMMA is determined by a threshold stress intensity factor $\left(K_{\mathrm{m}}\right)$ [4] or a minimum surface energy required for craze formation $\dagger\left(R_{\mathbf{i}}\right)[2$, $3]$. For a typical edge-cracked tensile specimen with a starter crack length $\left(a_{i}\right)$ and a critical applied stress $\left(\sigma_{c}\right)$, these relations are given by

$$
E R_{\mathrm{i}}=K_{\mathrm{m}}^{2}=\sigma_{\mathrm{c}}^{2} Z a_{\mathrm{i}}
$$

where $E$ is the Young's modulus and $Z$ the finite width correction factor for the edge-cracked specimen.

\footnotetext{
* Present address: Department of Mechanical Engineering, Imperial College of Science and Technology, Exhibition Road, London, UK.

$\dagger$ In the present paper, $R_{i}$ is used instead of $T_{0}$ originally employed by Andrews and Bevan in $[2,3]$. Of course, $2 T_{0}=$ $R_{\mathrm{i}}$.
} 
Andrews and Bevan [2,3] have found that temperature $(T)$ is a vital stress-solvent crazing parameter. According to a cavitation theory, they have worked out the quasi-static work for formation of craze cavities, which is given by

$$
R_{\mathrm{i}}=4.84(h \gamma / \rho) f^{2 / 3}+0.66 Y \psi h f
$$

where $\gamma$ is the interfacial energy of the voids, $\rho$ the mean distance between the void centres, $f$ the void fraction, $h$ the craze thickness, $Y$ the shear yield stress and $\psi$ a constant with a value of 4.4 . The significant effects of temperature on $R_{\mathrm{i}}$ are reflected by the conditions that $Y=0$ for $T \geqslant T_{c}$ and $Y>0$ for $T<T_{\mathrm{c}} \dagger$. In a recent paper, Andrews et al. [6] have shown that $T_{c}$ is close to the glass transition temperature $T_{\mathrm{g}}$ of the equilibrated swollen material at the crack tip.

Strain rate $(\dot{\epsilon})$ is also a significant solvent-stress cracking parameter for viscoelastic polymers [1, 8]. A measure of the strain-rate sensitivity of a material may be represented by the functional dependence of fracture toughness $(R)$, or equivalently, stress intensity factor $\left(K_{\mathbf{c}}\right)$, on crack speed $(\dot{a})$. For example, definite $R(\dot{a})$ or $K_{\mathrm{c}}(\dot{a})$ relations for PMMA and PE immersed in a number of organic solvents, such as carbon tetrachloride, ethanol and methanol, have been determined $[1,8,12]$. More recently, Williams and Marshall [14] have shown that such $R(\dot{a})$ or $K_{\mathrm{c}}(\dot{a})$ relations can be predicted by incorporating a simple fluid model into a C.O.D. analysis [4].

A different approach has been used by polymer physicists and chemists in characterizing the crazing or cracking behaviour of plastics in the presence of organic solvents. Physically, the onset of environment-enhanced crazing in plastics at lower stresses and strains can be explained in terms of either a surface energy reduction mechanism [15] or a plasticization theory $[11,16-18]$. In general, there has been strong evidence [11] that the plasticization theory is the more important factor in solventstress crazing or cracking. By this theory, it is suggested that absorption of the liquid into the polymer will cause some plasticization which in turn lowers the $T_{\mathrm{g}}$ of the polymer. The lowering of $T_{\mathrm{g}}$ depends on the degree of plasticization which, to a first approximation, is dependent directly on the difference of the solubility parameters of the solvent $\left(\delta_{s}\right)$ and the polymer $\left(\delta_{p}\right)$. A method to characterize the environmental susceptibilities of plastic materials is to correlate the critical strain $\left(\epsilon_{c}\right)$ to cause craze or crack initiation in a three-point bending test with $\delta_{\mathrm{s}}$ for a spectrum of liquid environments. Good correlations between $\epsilon_{\mathrm{c}}$ and $\delta_{\mathrm{s}}$ have been obtained for polyphenylene oxide [17] in a complete range of liquids. Reasonably good correlations have also been reported for PMMA [19], PVC [19] and polysylphone [17], but only in non-polar liquids. As pointed out in $[11]$ and $[17,19]$ the size of the solvent molecules as well as liquid/polymer interactions via hydrogen bonding could interfere with the $\epsilon_{\mathrm{c}}-\delta_{\mathrm{s}}$ correlation technique.

It appears that nominal critical strain $\left(\epsilon_{\mathrm{c}}\right)$ or nominal critical stress $\left(\sigma_{\mathrm{c}}\right)$ are not appropriate parameters to describe fracture characteristics which involve work or energy input for crack or craze formation [4]. Andrews and Bevan [3] have suggested the use of $R_{\mathrm{i}}$ in place of $\epsilon_{\mathrm{c}}$ and have successfully shown that the minimum value of $R_{\mathrm{i}}$ (for $T>T_{\mathrm{c}}$ ) for craze initiation in PMMA is a smooth function of the difference $\left(\delta_{\mathrm{s}}-\delta_{\mathrm{p}}\right)$, both for pure organic solvents and for water/alcohol mixtures. The minimum of this curve occurs when $\delta_{\mathrm{s}} \simeq \delta_{\mathrm{p}}$. Justification of the use of $R_{\mathrm{i}}-\delta_{\mathrm{s}}$ correlation for other material/solvent systems can only be assessed when further experimental results are produced.

ABS is a rubber-reinforced styrene plastic widely used in industrial applications. Many studies have been performed by previous investigators [20-22] on its mechanical properties and source of toughness. Although the effects of temperature* on the Charpy impact energy of ABS have been investigated by Matsuo et al. [22], the fracture behaviour and mechanism of ABS when immersed in organic solvents have never been studied. The present paper reports some preliminary experimental results along these lines for a commercially available ABS (acrylonitrile-butadiene-styrene) plastic when fractured in a range of organic solvents.

In the present work, three major fracture aspects

$\dagger T_{\mathrm{c}}$ is a characteristic temperature reported in $[2,3]$, above which $R_{\mathrm{i}}$ assumes a minimum constant value and below which $R_{\mathrm{j}}$ increases linearly with decrease in $T$.

$\$ R$ is a symbol used in Gurney [13]. For quasi-static crack propagation $E R=b K^{2}$ where $b=1$ for plane stress and $\left(1-\nu^{2}\right)$ for plane strain. $\nu$ is the Poisson's ratio.

* Only for $T>T_{\mathrm{g}}$ is reported in [22]. The present author [32], however, has shown that for $T_{\mathrm{g}}>T>233 \mathrm{~K}, R$ or $K_{\mathrm{C}}$ increases with decrease in temperature. 
have been investigated. (1) Crack initiation toughness $\left(R_{\mathbf{i}}\right)$ or initiation stress intensity factor $\left(K_{\mathbf{i}}\right)$ was obtained as a function of a range of organic liquid environments with solubility parameters $\left(\delta_{\mathrm{s}}\right)$ different from the polymer. (2) The variations of fracture toughness $(R)$ or $\left(K_{\mathrm{c}}\right)$ as a function of crack speed $(\dot{a})$ for the polymer when immersed in three selected environments, namely, methanol, toluene and carbon tetrachloride, were investigated. (3) The fracture morphology of ABS fracture in the organic liquid environments was studied with the scanning electron microscope (SEM).

\section{Experimental methods}

\subsection{Material}

The ABS plastic used in the present investigation is a commercial product of Marbon (USA) Plastics Company. "Dumb-bell" shape testpieces were cut from the extruded sheets (of thickess $2.54 \mathrm{~mm}$ ) to determine the various mechanical properties by standard tensile tests. Some typical mechanical properties are: at cross-head rate $(\dot{u})=2 \mathrm{~cm} \mathrm{~min}^{-1}$, Young's modulus $(E)=1.75 \mathrm{GN} \mathrm{m}^{-2}$, yield stress $\left(\sigma_{\mathrm{y}}\right)=42 \mathrm{MN} \mathrm{m}^{-2}$ and maximum strain $(\epsilon)=12 \%$.

The organic solvents used in the cracking experiments were toluene, benzene, carbon tetrachloride, acetone, methanol, ethanol, isopropanol and water. All these liquids have solubility parameters different from that of the plastic. Except the alcohols and water which are crazing agents, all other solvents are strong swelling or cracking agents. Table I gives the values of the solubility parameters of these organic liquids [23].

\subsection{Cracking experiments}

\subsubsection{Crack initiation experiments}

Compact tension (CT) specimens with typical dimensions as shown in Fig. I were cut from the supplied ABS sheets. In the crack initiation studies, the specimens with given crack lengths $\left(a_{i}\right)$ were loaded in the Instron testing machine and the organic liquids were injected to the crack tips from squeeze bottles. The load $\left(X_{\mathrm{i}}\right)$ to cause crack initiation (not propagation) was "pipped" onto the recording chart by a remote pip control. To ensure accurate measurement of the crack initiation load, the specimen was illuminated by a distant light shining on its surface and the crack motion monitored by a travelling microscope. In those experiments where the liquids were nearly miscible with the solid polymer itself, the initiation load almost coincided with the maximum load before
TAB LE I Solvent solubility parameter $\left(\delta_{\mathrm{s}}\right)$ and hydrogen bonding parameter of various liquid environments

\begin{tabular}{lcc}
\hline Environment & $\delta_{\mathrm{S}}\left(\mathrm{cal} \mathrm{cm}^{-2}\right)^{\mathbf{1 / 2}}$ & $\begin{array}{l}\text { hydrogen } \\
\text { bonding } \\
\text { parameter }\end{array}$ \\
\hline Carbon tetrachloride & 8.60 & 0 \\
Toluene & 8.90 & 4.20 \\
Benzene & 9.20 & 0 \\
Acetone & 10.00 & 12.50 \\
Isopropanol & 11.50 & 16.70 \\
Ethanol & 12.70 & 17.70 \\
Methanol & 14.50 & 19.80 \\
Water & 23.50 & 39.00 \\
\hline
\end{tabular}

(1) $\delta_{s}$ values are taken from [23]. To convert to $\left(\mathrm{MJ} \mathrm{m}^{-3}\right)^{1 / 2}$ multiply by 2.05 .

(2) hydrogen bonding parameters are requoted from work of Vincent and Raha [19].

dropping off (because of subsequent crack propagation). However, in the alcohols and water, the crack initiation loads were always much less than the maximum loads.

The crack initiation stress intensity factors $\left(K_{\mathbf{i}}\right)$ could be calculated from the following equation [24],

$$
K_{\mathbf{i}}=Y\left(\frac{a_{\mathrm{i}}}{W}\right) \frac{X_{\mathrm{i}} V a_{\mathrm{i}}}{t W}
$$

where $Y\left(a_{1} / W\right)$ is the Gross-Srawley boundarycollocation coefficient, $a_{\mathrm{i}}$ the starter crack length, $t$ the thickness and $W$ the total length of CT specimen measured from the edge of back face to line of load application. The results of $K_{\mathbf{i}}$ or equivalently $R_{\mathrm{i}}$ for fracture initiation in the various organic liquids could then be correlated with their corresponding solvent solubility parameters $\left(\delta_{s}\right)$.

To provide a common basis of comparison of results in various liquids, the cross-head speed of the Instron was kept constant at $0.5 \mathrm{~cm} \mathrm{~min}^{-1}$, the temperature was about $298 \mathrm{~K}$ and the r.h. $\approx 70 \%$.

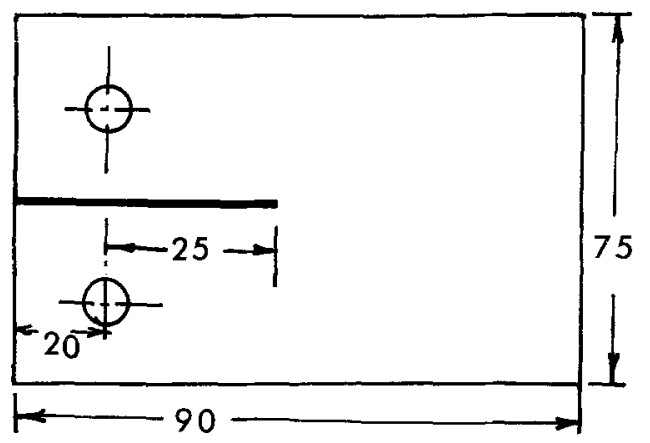

Figure 1 A compact tension specimen (all dimensions in $\mathrm{mm})$. 
The starter crack length was varied from 25 to 40 $\mathrm{mm}$.

\subsubsection{Crack propagation experiments}

In these crack propagation experiments, the main objective is to obtain a relationship between the fracture toughness $(R)$ or stress intensity factor $\left(K_{\mathrm{C}}\right)$ and the crack speed $(\dot{a})$ in a given liquid environment. Both compact tension and single-edge notch (SEN) specimens were used for this purpose.

In compact tension specimens, where quasi-static stable crack propagation was readily available, the fracture toughness values were calculated from the irreversible work area method pioneered by Gurney and co-authors $[13,25-28]$. Because cracking was stable, crack speeds could be measured easily by appropriate instrumentation such as described in Atkins et al. [29]. When the cross-head speeds were varied, which gave rise to various corresponding crack speeds, many $(R, \dot{a})$ data could be obtained easily.

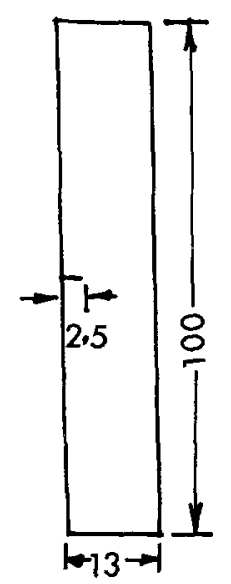

Figure 2 Single-edge-notched specimen (all dimensions in $\mathrm{mm}$ ).

The SEN specimens with typical dimensions were shown in Fig. 2. The starter edge crack length $\left(a_{\mathbf{i}}\right)$ was fixed at $2.5 \mathrm{~mm}$. By varying the cross-head speed $(u)$, and recording the time $\left(t_{\mathrm{f}}\right)$ to cause failure of the specimen in the given environment and the fracture load $(X)$, the apparent crack speed (a) could be worked out from a crack tip stress rate analysis given by Irwin [30] as

$$
\dot{a}=\frac{1}{\sqrt{2 \pi t_{\mathrm{f}}}}\left(\frac{K_{\mathrm{C}}}{\sigma_{\mathrm{y}}}\right)^{2}
$$

where $K_{\mathbf{C}}$ for the SEN specimen is given by an equation similar to Equation $3[24]$, and $\sigma_{y}$ is the yield stress of the polymer measured in the environment at the same cross-head speed $(\dot{u})$ as the cracking experiment. Thus, with sufficient experimental data collected, the $\left(K_{\mathrm{C}}, \dot{a}\right)$ relationship could be generated.

In all the environmental cracking experiments, organic solvents were injected to the crack tips and continuous contact of liquid environment with crack tip material was maintained. All cracking experiments were performed at a temperature range $298 \pm 2 \mathrm{~K}$ and $70 \%$ r.h.

\section{Results and discussion \\ 3.1. Fracture initiation and solvent solubility parameter}

The crack initiation stress intensity factor $\left(K_{\mathfrak{i}}\right)$ was obtained (from Equation 3 ) by plotting $\left[\left(X_{\mathrm{i}} / t W\right) Y\right.$ $\left.\left(a_{\mathrm{i}} / W\right)\right]$ against $a_{\mathrm{i}}^{-1 / 2}$ for different solvents. It was found that in the non-crazing agents (e.g. acetone, benzene and toluene) all experimental points fell within bounds of straight lines through the origin; however, in the alcoholds, the scatter of data was quite considerable so that only lower bound $K_{\mathrm{i}}$ values could be obtained. Fig. 3 shows the correlation of $K_{i}^{2}$ for ABS with the solvent solubility parameter $\left(\delta_{s}\right)$ of the different liquid solvents. The curve is similar to that reported by Andrews and Bevan [3] for PMMA in a series of aliphatic alcohols. It may be seen that $K_{\mathrm{i}}^{2}$ is a smooth function of $\delta_{\mathrm{s}}$ and has a minimum in the region where $\delta_{\mathrm{s}} \simeq$ $\delta_{\mathrm{p}}$. Note that $\delta_{\mathrm{p}}$ is about $9.3\left(\mathrm{cal} \mathrm{cm}^{-3}\right)^{1 / 2}$ for the present ABS plastic.

It must be pointed out that although $K_{\mathbf{i}}$ also correlates reasonably well with $\delta_{\mathrm{s}}$, a much broader minimum centred around $\delta_{\mathrm{s}} \simeq \delta_{\mathrm{p}}$ is obtained. This should be contrasted with the sharp minimum in the $K_{\mathrm{i}}^{2}-\delta_{\mathrm{s}}$ plot shown in Fig. 3. Since $K_{\mathrm{i}}^{2}=E R_{\mathrm{i}}$, and therefore represents work input or energy required for crack (craze) formation, it is perhaps a more realistic parameter than $K_{\mathbf{i}}$, which only represents the threshold stress intensity factor for crack (craze) initiation.

Since all fracture initiation experiments were performed at a constant temperature $(\simeq 298 \mathrm{~K})$, it is appropriate to discuss the possible effects of temperature variation on the $K_{i}^{2}\left(=E R_{i}\right)$ versus $\delta_{\mathrm{s}}$ correlation method. As shown by Andrews and Bevan $[2,3], K_{\mathbf{i}}^{2}$ is strongly dependent on temperature according to Equation 2 where $Y$, the shear yield stress, is a function of temperature. The minimum value of $K_{\mathrm{i}}^{2}$ therefore occurs when $Y$ is zero, which only happens when the temperature at which the experiments are performed exceeds or equals 


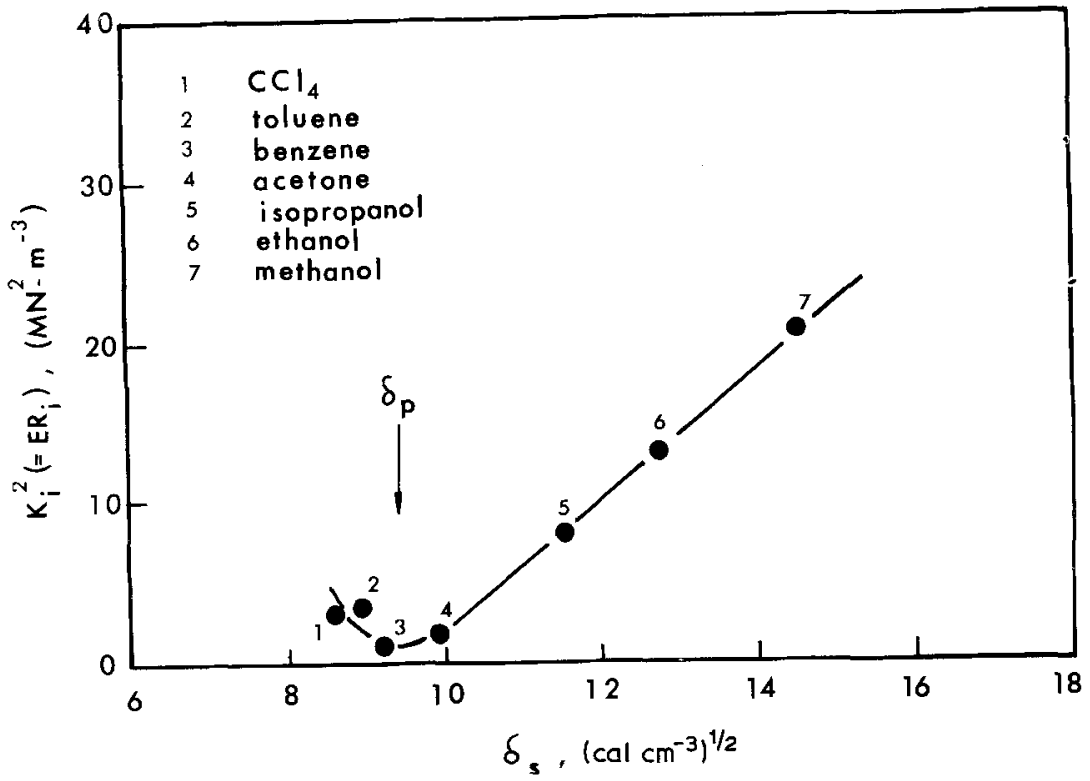

Figure 3 Correlations between $K_{\mathrm{i}}{ }^{2}$, stress intensity factor at crack initiation, and $\delta_{\mathrm{S}}$, solvent solubility parameter, for ABS [Datum for water $K_{\mathrm{i}}^{2}=50 \mathrm{MN}^{2} \mathrm{~m}^{-3}, \delta_{\mathrm{s}}=23.3\left(\mathrm{cal} \mathrm{cm}^{-3}\right)^{1 / 2}$ is not shown.]

the reduced glass transition temperature $\left(T_{\mathbf{g}}\right)$ of the crack tip material by solvent absorption. In the present studies, since $\mathrm{CCl}_{4}$, toluene, benzene and acetone are solvents readily miscible with the polymer, it is expected that their presence would cause the $T_{\mathrm{g}}$ of $\mathrm{ABS}$ to drop to or below the testing temperature of $298 \mathrm{~K}$. Consequently, $K_{\mathbf{i}}^{2}$ obtained in these solvents should be minimum values. As for the crazing agents, such as the alcohols and water, the $K_{\mathbf{i}}^{2}$ values presented in Fig. 3 are not necessarily minima. To find out the true minimum $K_{\mathrm{i}}^{2}$ in these crazing agents, it is necessary to conduct a series of similar experiments at varying temperatures. Some preliminary experimental results have shown that the $K_{i}^{2}$ value obtained for fracture initiation in water is probably a minimum because its magnitude (i.e. $K_{\mathrm{i}}^{2} \approx 50 \mathrm{MN}^{2} \mathrm{~m}^{-3}$ ) is more or less constant being independent of temperature in the region of 293 to $323 \mathrm{~K}$. Although at present we do not have minimum $K_{i}^{2}$ values for fracture initiation in the alcohols, we believe that (for the range of solvents we have used), if such minimum $K_{\mathbf{i}}^{2}$ values are obtained, the possible influence would be to affect slightly the convex geometry of the correlation line (in Fig. 3) by pushing down vertically point to point the portion of the curve right of the minimum. However, the significance of the plot (i.e. $K_{\mathrm{i}}^{2}-\delta_{\mathrm{s}}$ ) should still be maintained with the minimum of $K_{\mathrm{i}}^{2}$ in the region where the solubility parameters of the solvent and polymer are equal or nearly so (i.e. $\delta_{\mathrm{s}}-\delta_{\mathrm{p}} \simeq 0$ ).

It should also be important to note that in Andrews and Bevan's original $R_{\mathrm{i}}-\delta_{\mathrm{s}}$ plot for PMMA [3], the liquid environments employed were alcohols or water/alcohol mixtures which were only crazing agents. The present work shows that fracture initiation in $\mathrm{ABS}$ in the presence of different liquid environments, the $K_{\mathrm{i}}^{2}-\delta_{\mathrm{s}}$ correlation method can be usefully extended to accommodate both crazing and non-crazing (i.e. cracking and solvent) agents.* In some more recent experiments, we have shown further that the correlation technique by plotting $K_{\mathrm{i}}^{2}$ against $\delta_{\mathrm{s}}$ is also meaningful for environment-enhanced fracture initiation in glass. reinforced with random short glass fibres when fractured in a range of organic solvents. The minimum $K_{\mathrm{i}}^{2}$ also occurs in the region where $\delta_{\mathrm{s}}$ of the solvent equals $\delta_{p}$ of the glass-filled polystyrene. Also shown in Fig. 4 is a similar plot for plain polystyrene injection moulded in our laboratory. While Kambour et al. [11] have not been able to obtain good correlation between $\epsilon_{\mathrm{c}}$ and $\delta_{\mathrm{s}}$ for PS because of the limited range of $\epsilon_{\mathrm{c}}$ available, the results shown here suggest that there are reasonable correlations between $K_{i}^{2}$ and $\delta_{\mathrm{s}}$ (for the range of solvents employed).

Finally, a few words should be mentioned about the effects of hydrogen bonding on the $\epsilon_{\mathrm{c}}-\delta_{\mathrm{s}}$

* Cracking and solvent agents are close to the minimum where $\delta_{\mathrm{s}} \simeq \delta_{\mathrm{p}}$ and crazing agents spread further away. 


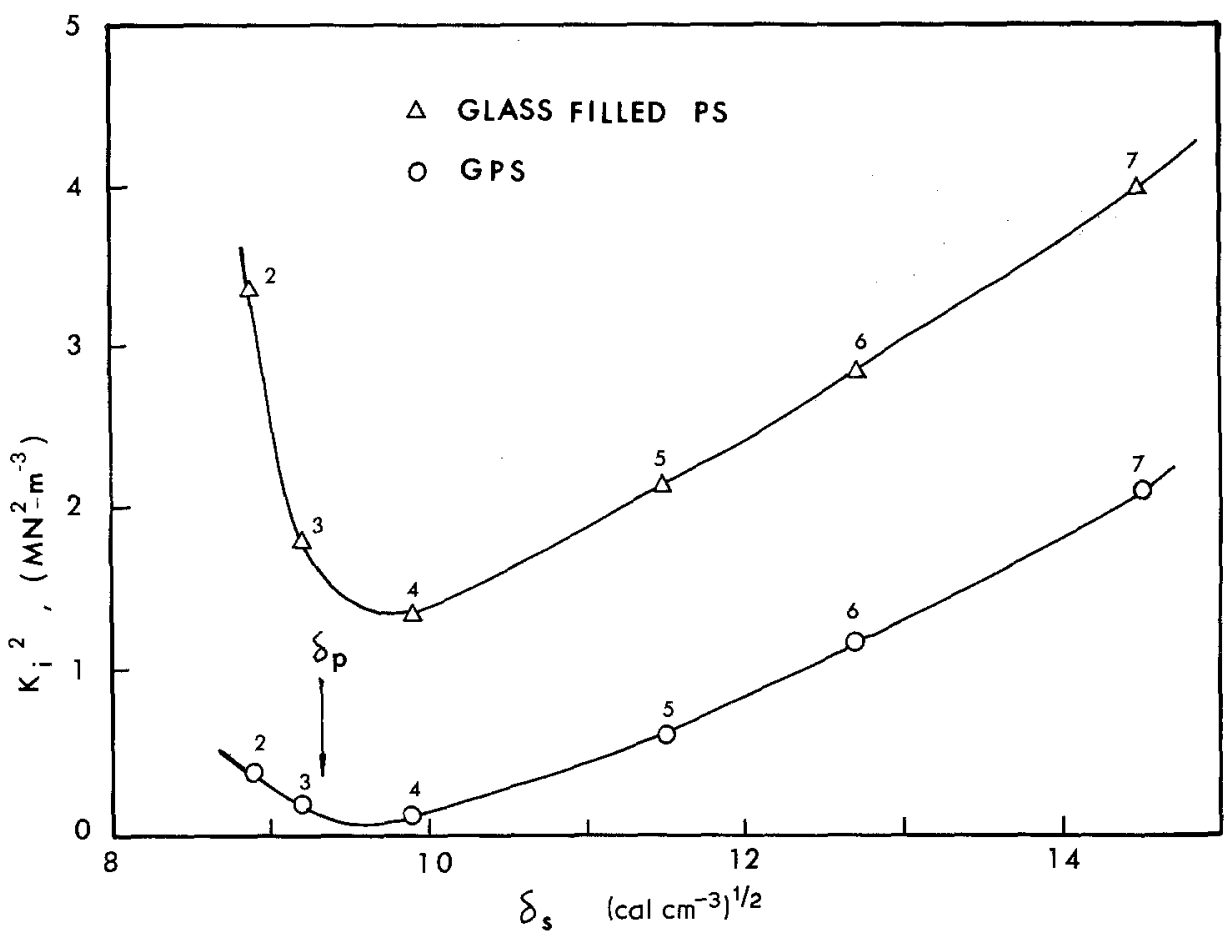

Figure 4 Correlations between $K_{\mathrm{i}}^{2}$ and $\delta_{\mathrm{s}}$ for glass-filled and plain polystyrene. Numbers on symbols represent solvents denoted in Fig. 3.

correlations $[19,31]$. For example, Vincent and Raha [19] have shown that in environmental stress cracking of PMMA in a wide range of liquids, the $\left(\epsilon_{c}, \delta_{s}\right)$ data obtained do not appear to have any correlations. This fact is clearly brought out when all the data reported in [19] are replotted in Fig. 5. However, if a curve is drawn through the $\left(\epsilon_{\mathrm{c}}, \delta_{\mathrm{s}}\right)$ points for those liquids with $\delta_{\mathrm{h}}=0$ (see Fig. 5), there are definitely good correlations, which give a pronounced minimum in $\epsilon_{\mathrm{c}}$ near the solubility parameter of PMMA. It is therefore thought [19] that the bad correlation between $\epsilon_{\mathrm{c}}$ and $\delta_{\mathrm{s}}$ for the whole spectrum of liquids is a consequence of possible liquid/polymer interactions through hydrogen bonding. However, in the $K_{i}^{2}-\delta_{s}$ plots presented here for ABS, glass-filled polystyrene and PS and that for PMMA [3], the effects of hydrogen bonding do not appear to be significant for the range of liquids used. This perhaps is yet another advantage of using $K_{\mathrm{i}}^{2}$ in place of $\epsilon_{\mathrm{c}}$ when correlating with $\delta_{\mathrm{s}}$. Of course, more data from experiments involving a much wider range of liquids have to be gathered before a more conclusive statement can be made.

\subsection{Comparison of fracture toughness in liquid environment}

Table II compares the fracture toughness of ABS 308 when immersed in different liquid environments. Since fracture resistances are dependent on crack speed and temperature, it is necessary to choose a common combination of crack speed and temperature as a basis for comparison. In the present case,

T ABLE II Comparison of fracture toughness for ABS in different liquid environments (Crack speed $\approx 0.10 \mathrm{~mm}$ $\sec ^{-1}$ at $298 \mathrm{~K}$ )

\begin{tabular}{lc}
\hline Environment & $R\left(\mathrm{~kJ} \mathrm{~m}^{-2}\right)$ \\
\hline Benzene & $2.0-3.0$ \\
Acetone & $1.0-2.5$ \\
Carbon tetrachloride & $2.0-2.5$ \\
Toluene & $6.0-7.0$ \\
Methanol & $20.0-24.0$ \\
Ethanol & $18.0-21.0$ \\
Isopropanol & $14.0-15.0$ \\
Air & $12.0-13.0$ \\
\hline
\end{tabular}

a crack speed of $0.1 \mathrm{~mm} \mathrm{sec}^{-1}$ and a temperature of $298 \mathrm{~K}$ are chosen as references. It may be seen that for those "non-crazing" agents, such as $\mathrm{CCl}_{4}$, acetone, benzene etc., the fracture toughness values are usually low, when compared with the corresponding value of 12 to $13 \mathrm{~kJ} \mathrm{~m}^{-2}$ in air. The large reduction in fracture resistance of ABS in these liquid environments is always accompanied by some dissolution of the polymer, which suggests that less external work or strain energy input is 


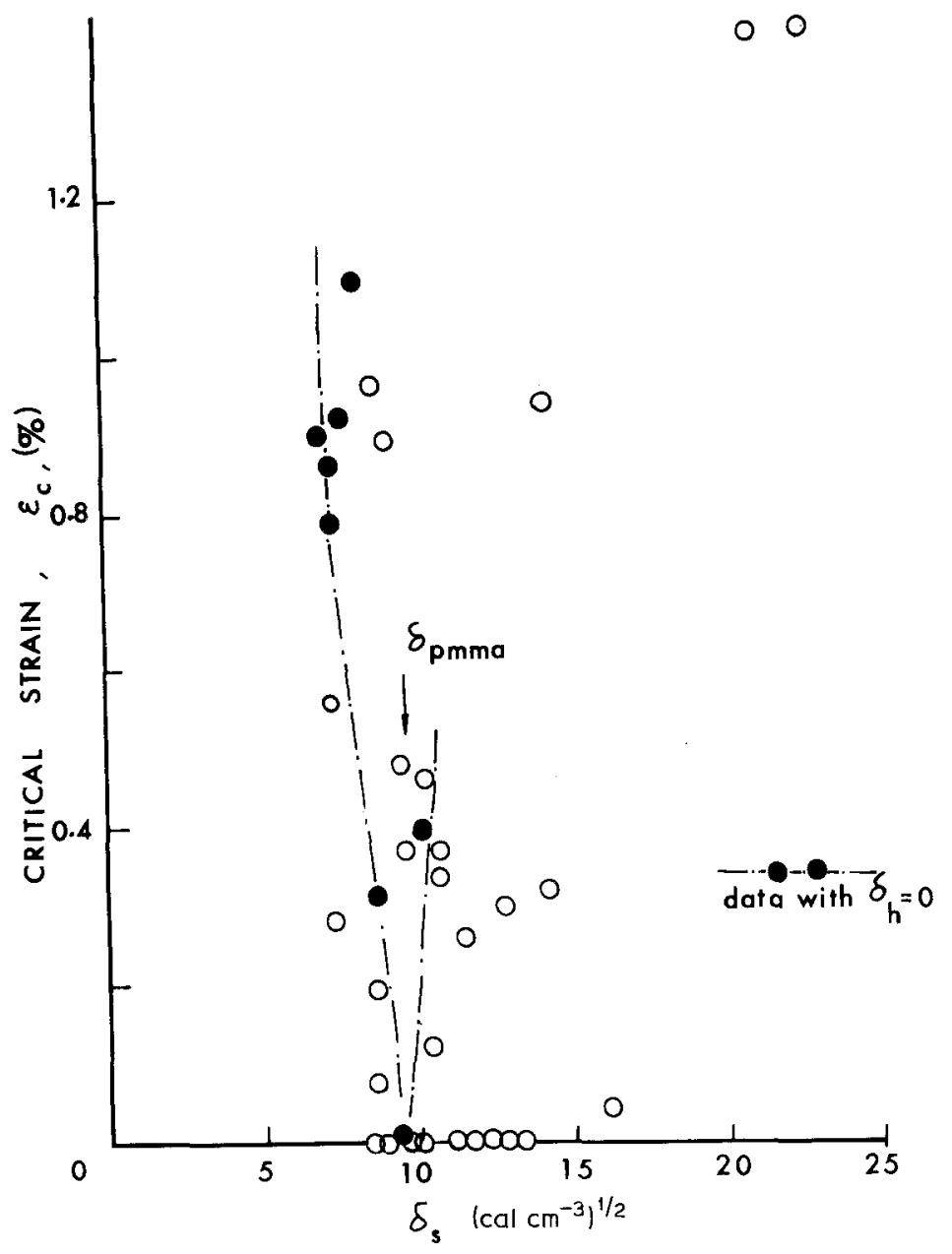

Figure 5 Correlations between $\epsilon_{\mathrm{c}}$, critical strain, and $\delta_{\mathbf{S}}$ for PMMA. (After Vincent and Raha, [19].)

required to cause separation and thus creation of new surfaces. On the contrary, the fracture toughness of ABS in the "crazing" agents (i.e. the alcohols) is greater than that in air. This perhaps is not surprising if one realizes the fact that crazes are energy sinks [8] and that during crack propagation in these solvents both new crack surfaces and crazes are simultaneously generated so that the work of fracture is greater. It is also important to see that the continuous generation of crazes at the crack tip region has a self stabilizing effect which promotes stable cracking.

\subsection{Fracture toughness and crack velocity relationship}

In this section, we will present the $R$ versus $\dot{a}$ curves for $\mathrm{ABS}$ in three typical liquid environments in which the fracture toughness values are readily calculated from Gurney's irreversible work area method for quasi-static crack propagation [25-28] . Then, in unstable cracking experiments, such as in
SEN specimens, where $R$ is not readily obtainable, $K_{\mathrm{C}}$ versus $\dot{a}$ curves are presented instead, where $K_{\mathbf{C}}$ and $\dot{a}$ can be estimated from appropriate equations. These results are discussed with reference to a recent analysis presented by Williams and Marshall [14] for environmental crack and craze growth in polymers.

Figs. 6 to 8 show the relations between $R$ and $\dot{a}$ for cracking of ABS in toluene, carbon tetrachloride and methanol respectively. As indicated in the figures, the experimental $(R, \dot{a})$ data were obtained from stable cracking experiments using both CT and SEN specimens. It was first thought that cracking would be unstable in SEN testpieces because of the poor geometrical stability factor [25] at small crack lengths; and that only apparent crack speeds $(\dot{a})$ could be calculated using Equation 4. However, experiments showed that cracking was stable at low cross-head speeds, thus $R$ and $\dot{a}$ could be calculated in the same way as in $\mathrm{CT}$ specimens using the quasi-static approach. At high cross-head 


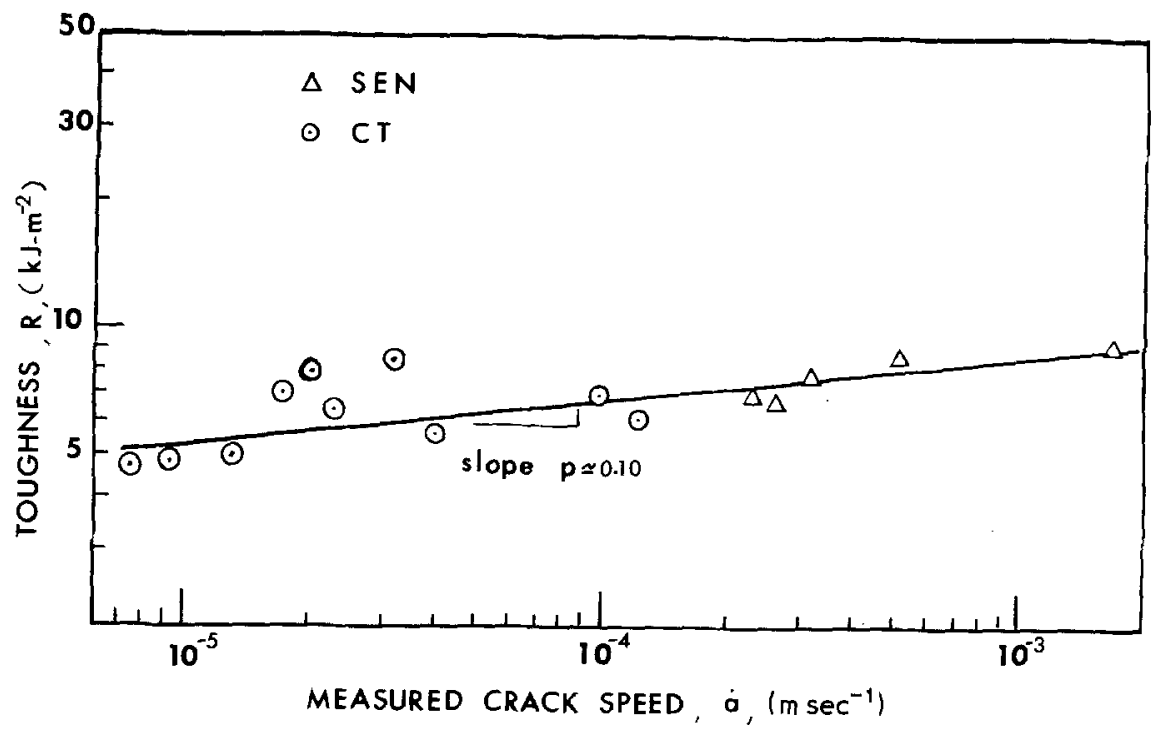

Figure 6 Variations of fracture toughness $(R)$ with meausred crack speed $(\dot{a})$ for ABS in toluene.

speeds, cracking was catastrophic in SEN specimens so that apparent $\dot{a}$ had to be calculated using Irwin's analysis [30] and $K_{\mathrm{C}}$ estimated from reference [24]. To convert $K_{\mathrm{C}}$ to equivalent $R$ values, the rate dependence of the Young's modulus $(E)$ must be known. Since we do not have any knowledge for the variation of $E$ with $\dot{a}$ for $\mathrm{ABS}$, these $\left(K_{\mathbf{C}}, \dot{a}\right)$ data cannot be converted to equivalent $(R, \hat{a})$ data and thus have not been included in Figs. 6 to 8 .

The correlations as shown in these figures are good for toluene and carbon tetrachloride but fair for methanol. In general, it may be shown that an equation of the form

$$
R=F \dot{a}^{p}
$$

can fit all the data reasonably well, where $F$ and $p$ are constants depending on the liquid environment, temperature and fracture mode. The values of $p$ are $0.10,0.10$ and 0.06 for toluene, carbon tetrachloride and methanol, respectively. We would now like to compare these results with a recent model for environmental crack and craze growth in polymers as suggested by Williams and Marshall [14].

By considering a crack tip opening displacement (C.O.D.) analysis in terms of time dependent material parameters (e.g. $\sigma_{y}$ and $E$ ), and in conjunction with a simple fluid flow model (when liquid environment passes through the porous and crazed structure of the crack tip region), Williams

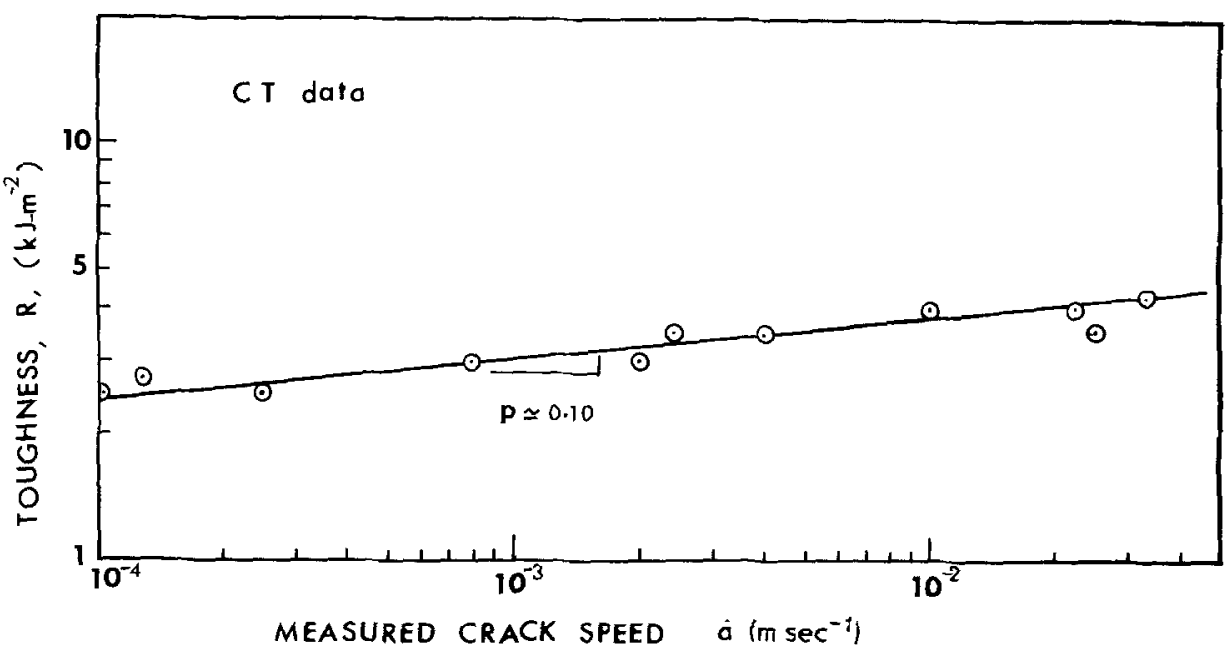

Figure 7 Variations of fracture toughness with measured crack speed for ABS in carbon tetrachloride. (Data from CT specimens.) 


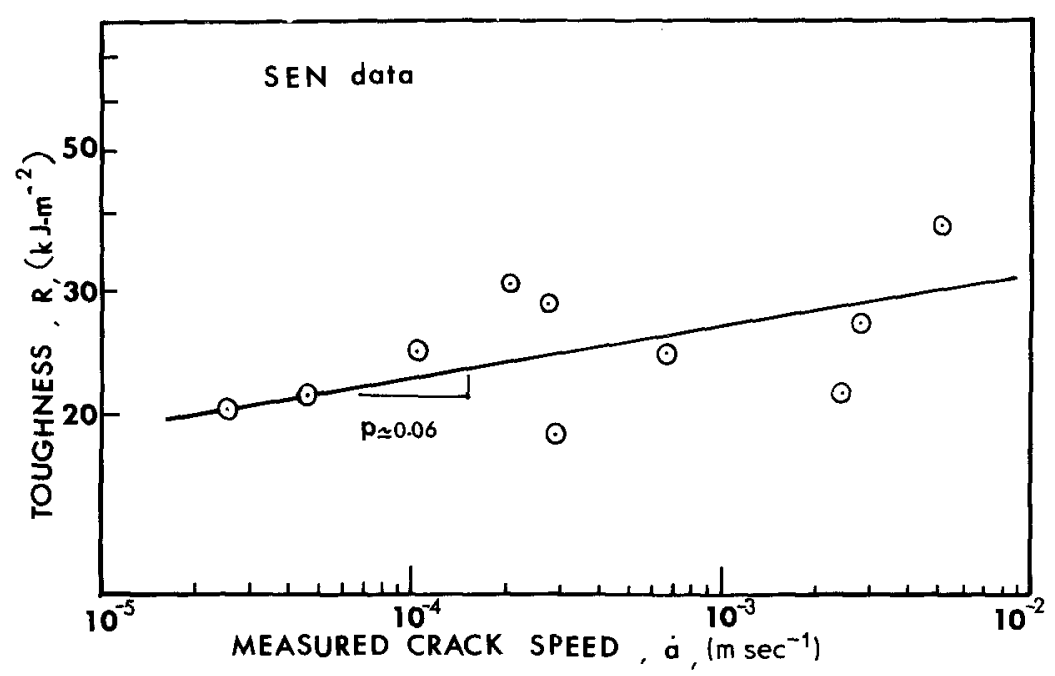

Figure 8 Variations of fracture toughness with measured crack speed for ABS in methanol. (Data from SEN specimens.)

and Marshall [14] have derived equations regarding craze and crack growth in polymers and glasses under both relaxation and flow controlled conditions. For relaxation controlled crack growth in liquid environments, they give the following $K_{\mathrm{C}}(\dot{a})$ relationship as

$$
K_{\mathrm{C}}=H \dot{a}^{(m+n) / 2(1-m+n)}
$$

where $H$ is a function of the crack tip opening displacement (C.O.D.), unit time values of the Young's modulus $\left(E_{0}\right)$ and yield stress $\left(\sigma_{0}\right) . m$ and $n$ are measures of the time dependent response of yield stress and modulus respectively.

Since $K_{\mathrm{C}}^{2}=E(\tau) R$, where $E(\tau)$ is the time $(\tau)$ dependent modulus, we can convert Equation 6 to an $R(\dot{a})$ equation, which is

$$
R=J \dot{a}^{(m / 1-m+n)} .
$$

Note that Equation 7 is of the same form as Equation 5 so that $p=m /(1-m+n), J=F$. Because the environmental crack propagation experiments described in the present work are relaxation controlled, it is desirable to compare the measured values for $p$ with $m /(1-m+n)$. By assuming $m$ and $n$ of ABS to be comparable with those of rubber-modified polystyrene, we have from Table $I$ in [14], $m=0.078$ and $n=0.007$. Hence the theoretical slope (i.e. $m /(1-m+n)$ of a $\log -\log$ plot of $R$ and $\dot{a}$ should be 0.084 . This value compared with $p=0.10$ for both toluene and carbon tetrachloride and $p=0.06$ for methanol is acceptable because we have not taken into account of the effects of plasticization on $m$ and $n$. If plasticization due to environment absorption is to increase $m$ only and not $n$, then $p$ or $m /(1-m+n)$ should be increased in magnitude as well. Thus, we can explain why in methanol, $p(=0.06)$ is less than that in toluene and carbon tetrachloride $(0.10)$, presumably because of a greater plasticization effect in ABS by the "cracking" agents than the "crazing" liquid.

In the relaxation controlled crack growth behaviour, a distinct fracture criterion is that the C.O.D. is a constant, the increase in $K_{\mathrm{C}}$ or $R$ values with crack speed is only a direct consequence of the rate dependent $E$ and $\sigma_{y}$, both of which increase with $\dot{a}$. By fracture mechanics analysis, it can be shown that

$$
\text { C.O.D. }=R / \sigma_{\mathrm{y}} \text {. }
$$

Some typical values of C.O.D. calculated from results of these experiments for crack propagation in ABS are: (1) in toluene, 0.25 to $0.29 \mathrm{~mm}$; (2) in carbon tetrachloride, $0.07 \mathrm{~mm}$; (3) in methanol, $0.63 \mathrm{~mm}$; and (4) in air, $0.43 \mathrm{~mm}$. Obviously, such C.O.D. magnitudes are many times greater than those in brittle glassy plastics (e.g. $2 \mu \mathrm{m}$ in PMMA) but are comparable to those of tough and ductile polymers (e.g. $1 \mathrm{~mm}$ in PVC and $0.8 \mathrm{~mm}$ in PC).

Returning now to the $K_{\mathrm{C}}(\dot{a})$ relationship for crack propagation of ABS in organic solvents, we note that the apparent crack speeds $(\dot{a})$ depend on $\sigma_{y}$ (see Equation 4) which also varies with crosshead speeds and environment. Experiments were, therefore, run on standard tensile testpieces to establish the information of $\sigma_{\mathrm{y}}=\sigma_{\mathrm{y}}(\dot{u})$ in toluene and methanol. These results are shown in Fig. 9. It is noted that $\sigma_{\mathbf{y}}$ is rate sensitive in both toluene and methanol, and increases with cross-head speed over the range of 0.05 to $2.5 \mathrm{~cm} \mathrm{~min}^{-1}$. However, 


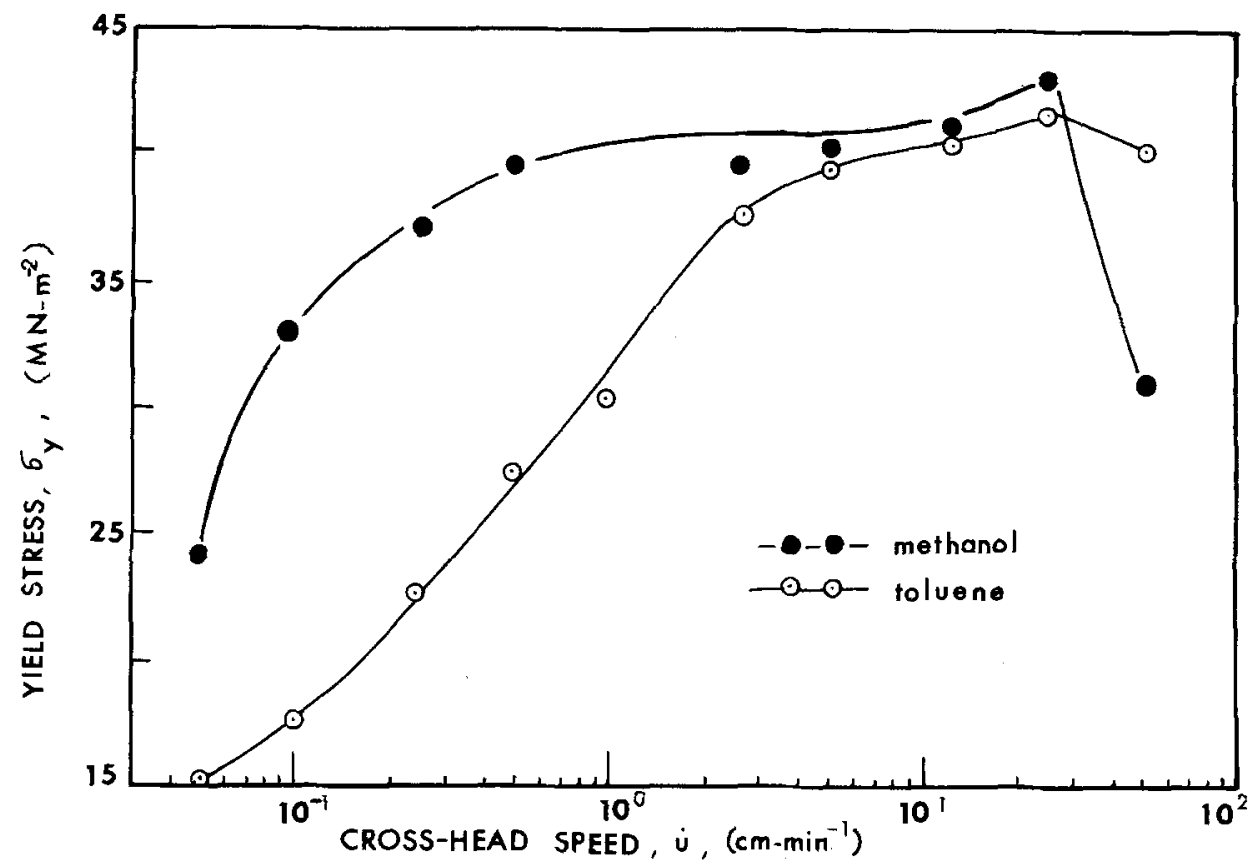

Figure 9 Relationship between yield stress $\left(\sigma_{\mathrm{y}}\right)$ and cross-head speed $(\dot{u})$ in methanol and toluene.

at higher cross-head speeds (i.e. 2.5 to $25 \mathrm{~cm}$ $\min ^{-1}$ ), $\sigma_{y}$ appears to remain constant at $41 \mathrm{MN}$ $\mathrm{m}^{-2}$. It should be mentioned that at low cross-head speeds, because the liquid environment has sufficient time to "damage" the material, fracture may, therefore, occur at a stress $\left(\sigma_{\mathrm{c}}\right)$ below the yield stress $\left(\sigma_{\mathbf{y}}\right)$. When it is difficult to distinguish $\sigma_{\mathrm{y}}$ from $\sigma_{\mathrm{c}}$, it is necessary to calculate $\sigma_{\mathrm{y}}$ using the maximum load of the load-displacement curve.

Fig. $10 \mathrm{a}$ and $\mathrm{b}$ show the $K_{\mathrm{C}}(\dot{a})$ relations for ABS in methanol and toluene respectively. All data were obtained from SEN specimens*. Apparently, there are fairly good correlations between $K_{\mathrm{C}}$ and $\dot{a}$ in toluene, and only fair correlations in methanol. The slopes in these logarithmic plots are 0.165 and 0.130 for toluene and methanol respectively. The theoretical slope calculated from Equation 6, with $m=0.078$ and $n=$ 0.007 [14], gives a value of 0.046 . Clearly, this magnitude is much smaller than the experimental values. However, if we take $m=n \simeq 0.10$, a not unreasonable assumption for most polymers, the predicted slope would be approximately 0.10 . Further, if plasticization effect is also considered, the slope will be even greater and, therefore, closer to the experimental results. Another probable source of error lies on the evaluation of apparent crack speed using Irwin's analysis [30], where $\sigma_{y}$ may have been underestimated at low cross-head rates because of early failure at stresses before yield.

Since in many polymers, $m$ and $n$ have magnitudes of approximately 0.10 [14], it is interesting to note that in the logarithmic plots of either $K_{\mathrm{C}}$ versus $\dot{a}$ or $R$ versus $d$, the same theoretical slopes of 0.10 are predicted from Equations 6 and 7 . However, when $E$ is rate or time independent (i.e. $n=0$ ), the relative slopes should differ by a factor of 2 .

\subsection{Fracture morphology of $A B S$ in organic solvents}

The fracture surfaces of ABS are stikingly different between the "crazing" (i.e. alcohols) and "noncrazing" (i.e. acetone, carbon tetrachloride, toluene etc.) liquid environments. Fig. 11a and b show a side view of the fracture appearance of a CT ABS specimen immersed in methanol. The crack tip region is clearly surrounded by a lot of surface crazes and the crack path is observed to run along and across the craze lines in a zig-zag manner. In pictures not shown here, advanced nucleation of minute cracks ahead of the main crack front is also frequently observed. These minute cracks usually coalesce with the main crack at a later stage of the cracking event. Such a crazing phenomenon

* The SEN specimens used in the methanol $\left(K_{\mathbf{C}}, \dot{a}\right)$ tests were made from a different sheet of ABS. 

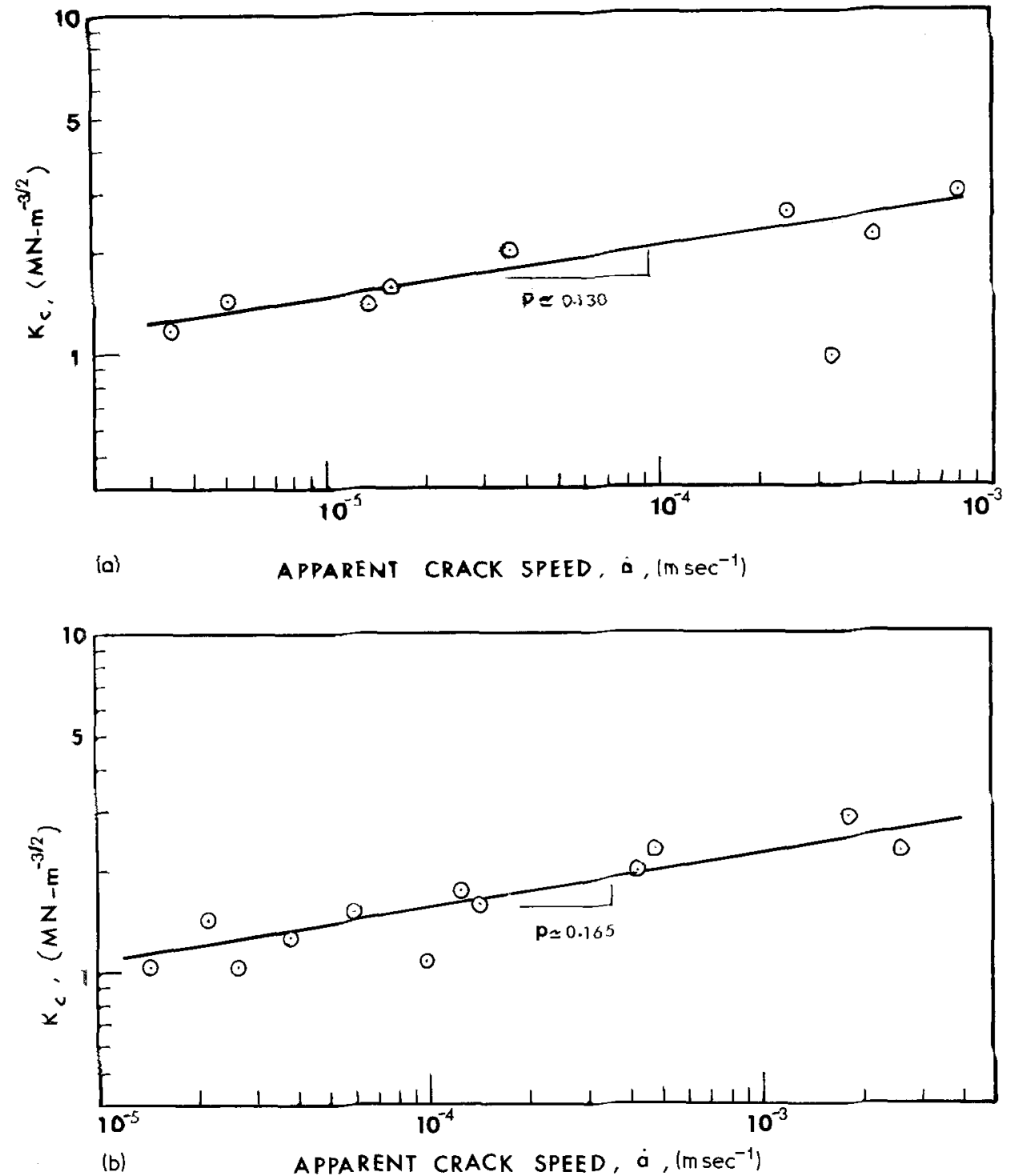

Figure 10 Variations of critical stress intensity factor $\left(K_{C}\right)$ and apparent crack speed (a) for ABS in (a) methanol and (b) toluene. (All data from SEN specimens.)

is common to all the alcohols used in the present work. Contrary to this fracture behaviour, Fig. 12 shows a side view of a similar CT specimen fractured in toluene. There are no surface crazes formed at the crack tip region, but indications that "dissolution" effects have occurred in the plastic are obvious because the sharp edges of the fracture surfaces expected (c.f. Fig. 11 a and b) have been rounded off by the action of the solvent. Similar dissolution effects have also been observed in acetone, benzene and carbon tetrachloride.

This remarkable difference in fracture appearance is more obvious when the fracture surfaces are examined using the SEM. Fig. 13 shows a rather featureless fracture surface of ABS in acetone, and it is surmized that the solution effect of acelone may have removed all details of the fracture plane. As opposed to this, Fig. 14 shows a typical rough region (near crack initiation zone) of $\mathrm{ABS}$ in methanol. Although not very obvious in this picture, there have been indications of some ductile plastic flow of the polymer along the propagation direction of the crack. Fig. 15 takes a closer look at the fracture surface of ABS in methanol neas the location 'A' marked in Fig. 11b. As shown, the region near the edge is very rough and must be associated with the crazing effect due to stressinduced absorption of methanol from the sides of 

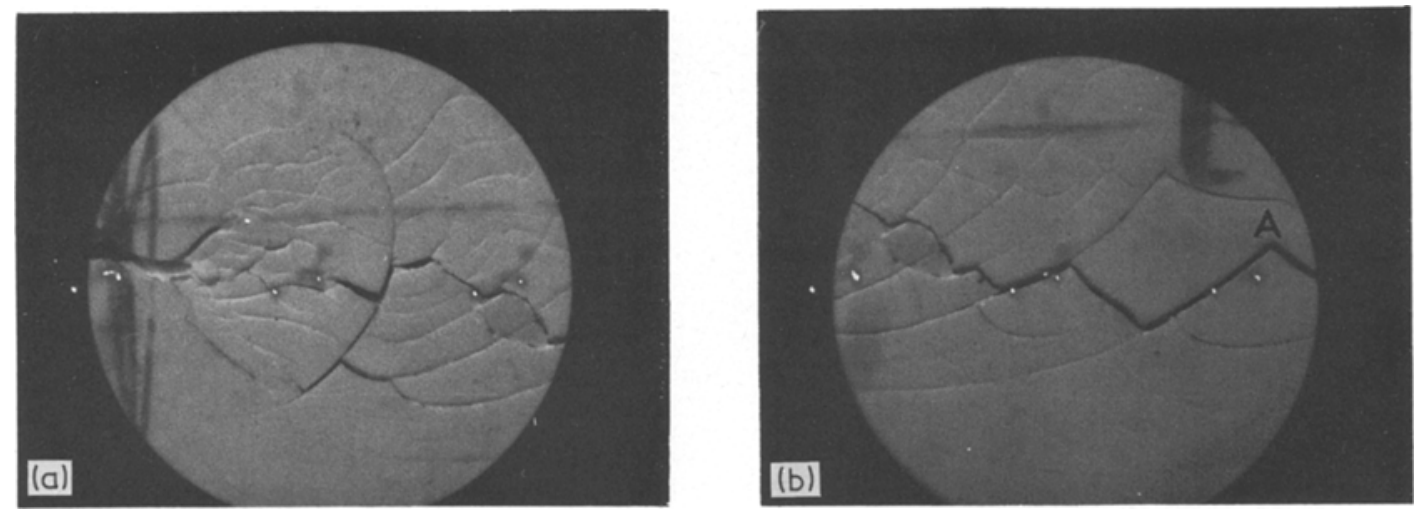

Figure 11 Fracture appearance of ABS (showing side view) in methanol. Note crazes at crack tip and crack path along crazes, (a) $\times 6.85$; (b) $\times 13.70$

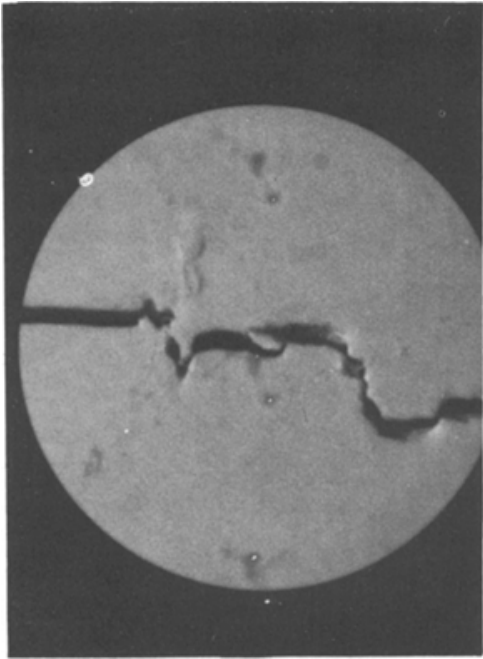

Figure 12 Fracture appearance of ABS (side view of crack tip region) in toluene. Crack direction from left to right $(\times 13.70)$.

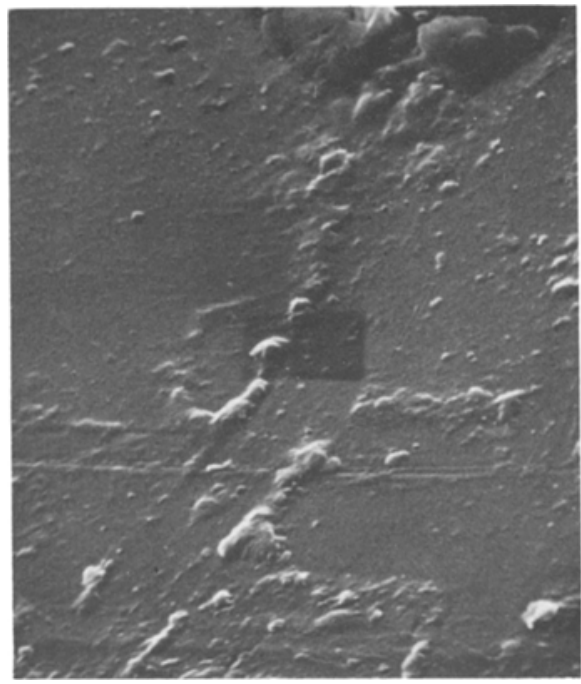

Figure 13 Typical fracture surface of ABS in acetone (X 3900). the specimen. More interesting features are observed when this particular region is magnified in Figs. 16 and 17. The honeycomb structure shown in Fig. 16 is an indication of environment-induced crazing after effects. It is difficult to see whether the rubber particles dispersed in the matrix have been desocketed due to this effect or not although one may expect this to happen. Fig. 17 shows, in much greater details, the remarkable plastic flow of the polymer in the cracking direction as induced by the softening action of methanol. The co-existence of these two obviously different features at failure at about the same location of the fracture surface suggests that in methanol (which is typical of a crazing agent to $\mathrm{ABS}$ ), the mechanisms of fracture

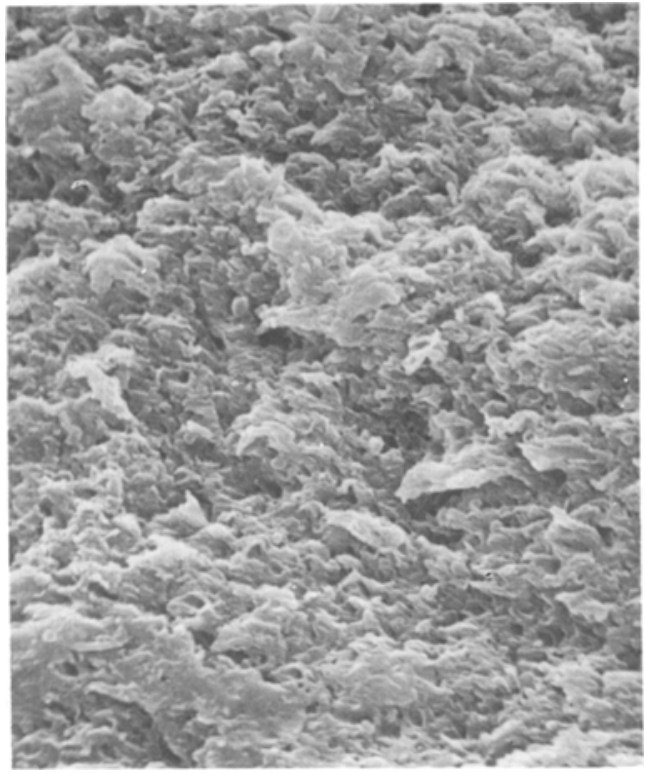

Figure 14 Typical fracture surface of ABS in methanol (near crack initiation region). Crack direction from right to left $(\times 2200)$. 


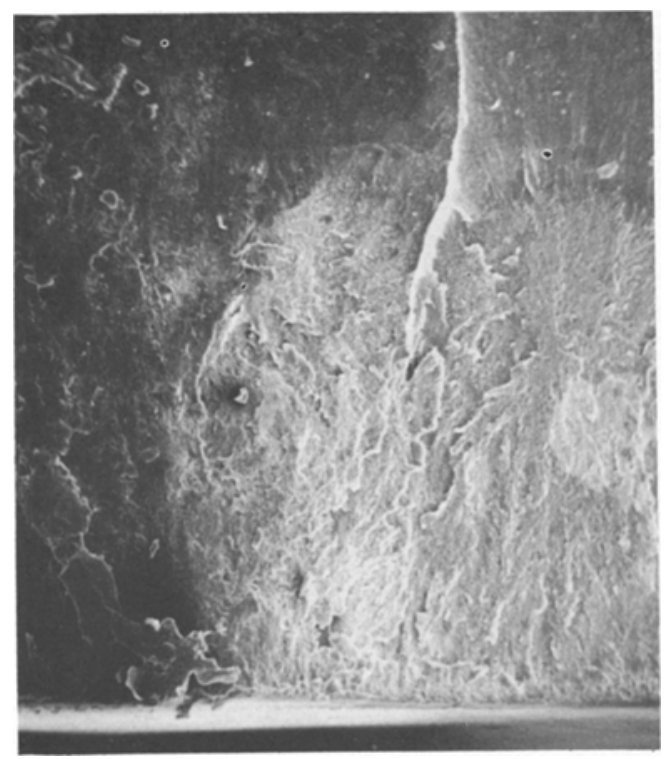

Figure 15 Crazed surface of location "A" in Fig. 11b. Crack direction from left to right $(\times 75)$.

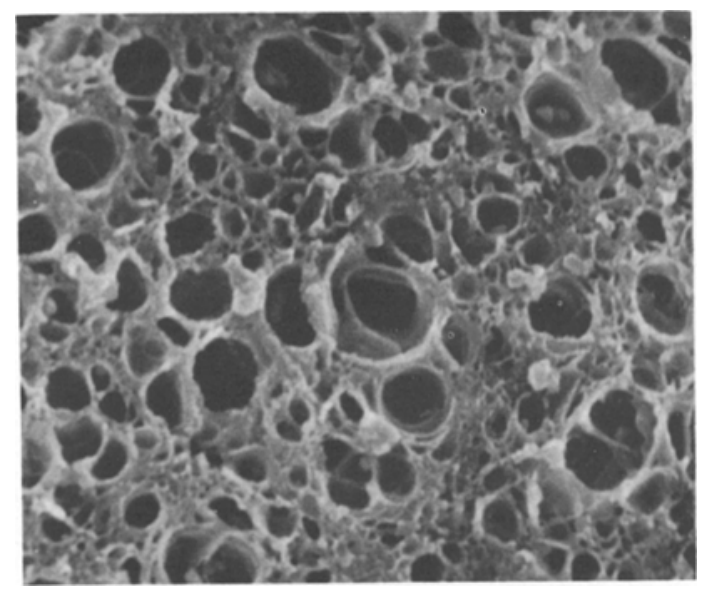

Figure 16 Honeycomb structure of a crazed surface in methanol $(\times 6500)$.

probably involve, simultaneously, the generation of craze cavities and local plastic deformation of the material, both of which are enhanced by environmental absorption.

\section{Conclusions}

The fracture behaviour of ABS in organic liquid environments has been presented in earlier sections of this paper. In summary, from fracture initiation studies, it has been shown that $K_{\mathrm{i}}^{2}$ or $E R_{\mathrm{i}}$ is a smooth function of the solvent solubility parameter $\left(\delta_{\mathrm{s}}\right)$, which gives a minimum at $\delta_{\mathrm{s}} \simeq \delta_{\mathrm{p}}$. For the limited range of liquid environments used, hydrogen bonding does not seem to have any significant effects on the correlations.

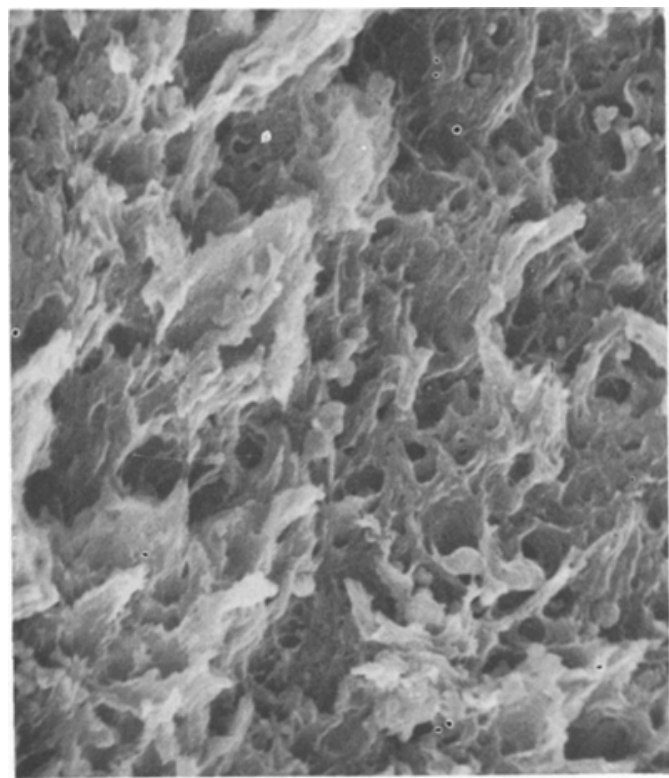

Figure 17 Typical ductile fracture surface (of a crazed surface) showing plastic flow in the direction of crack propagation (left to right). Note fine particles dispersed over fracture surface $(\times 7300$, methanol).

Crack propagation of ABS in toluene, carbon tetrachloride and methanol is a relaxation controlled process. Definite relations between $R$ and $\dot{a}$ exist, which agree well with a recent theoretical analysis due to Williams and Marshall [14]. Finally, for a given crack speed, experiments show that ABS possesses greater fracture toughness in alcohols than in "non-crazing" agents such as toluene, benzene and carbon tetrachloride.

\section{Acknowledgement}

The author is grateful to Professor A. G. Atkins for helpful discussions on this paper.

\section{References}

1. G. P. MARSHALL, L. E. CULVER and J. G. WILlIAMS, Plastics and Polymers, April (1970) 95.

2. E. H. ANDREWS and L. BEVAN, "Physical Basis of Yield and Fracture" (Institute of Physics, London, 1966) p. 209

3. Idem, Polymer 13 (1972) 337.

4. G. P. MARSHALL, J. E. CULVER and J. G. WILliamS, Proc. Roy. Soc. London A319 (1970) 165.

5. E. H. ANDREWS and G. M. LEVY, Polymer 15 (1974) 599.

6. E. H. ANDREWS, G. M. LEVY and J. WILLIS, $J$. Mater. Sci. 8 (1973) 1000.

7. Y. W. MAI, ibid 9 (1974) 1896.

8. Idem, ibid 10 (1975) 943.

9. C. GURNEY and Z. BORYSOWSKY, Proc. Phys. Soc. A61 (1948) 446. 
10. R. P. KAMBOUR et al., Macromolecules 7 (1974) 248.

11. idem, J. Appl. Polymer Sci., Polymer Physics Edn. 11 (1973) 1879.

12. I. D. GRAHAM et al., Proc. Dynamic Crack Propagation Conference, Lehigh University, (1972).

13. C. GURNEY, "Physical Basis of Yield and Fracture" (Institute of Physics, London, 1966) p. 3.

14. J. G. WILLIAMS and G. P. MARSHALL, Proc. Roy. Soc. A342 (1975) 55.

15. R. L. BERGEN, SPE J. 24 (1968) 77.

16. B. MAXWELL and L. F. RAHM, Ind. Eng. Chem. 41 (1949) 1988.

17. G. A. BERNIER and R. P. KAMBOUR, Macromolecules 1 (1968) 393.

18. R. P. KAMBOUR et al, ibid 5 (1972) 335.

19. P. I. VINCENT and S. RAHA, Polymer 13 (1972) 283.

20. MASATO MATSUO, Polymer 7 (1966) 421.

21. M. MATSUO et al., Polymer Eng. and Sci. 9 (1969) 206.
22. Idem, ibid. 10 (1970) 257.

23. H. BURREL and E. H. IMMERGUT, "Polymer Handbook" (Interscience, New York, 1966).

24. W. F. BROWN and J. E. SRAWLEY, ASTM STP 410 (1966).

25. C. GURNEY and Y. W. MAI, Eng. Fract. Mech. 4 (1972) 853.

26. C. GURNEY and J. HUNT, Proc. Roy. Soc. London A299 (1967) 509.

27. C. GUKNEY and K. M. NGAN, ibid A325 (1971) 207.

28. C. GURNEY, Y. W. MAI and R. C. OWEN, ibid A340 (1974) 213.

29. A. G. ATKINS, C. S. LEE and R. M. CADDELL, J. Mater. Sci. 10 (1975) 1381, 1394.

30. G. R. IRWIN, Appl. Mat. Res. 3 (1964) 65.

31. L. F. HENRY, Polymer Eng. and Sci. 14 (1974) 167.

32. Y. W. MAI, unpublished research, University of Michigan (1975).

Received 9 June and accepted 28 August 1975. 